\title{
Comparative microstructures and cytotoxicity assays for ballistic aerosols composed of micrometals and nanometals: respiratory health implications
}

\author{
This article was published in the following Dove Press journal: \\ International Journal of Nanomedicine \\ 18 January 2011 \\ Number of times this article has been viewed
}

\author{
Brenda I Machado' \\ Raquel M Suro² \\ Kristine M Garza ${ }^{2}$ \\ Lawrence E Murr ${ }^{1}$ \\ 'Departments of Metallurgical and \\ Materials Engineering, ${ }^{2}$ Biological \\ Sciences, The University of Texas \\ at EI Paso, TX, USA
}

\begin{abstract}
Aerosol particulates collected on filters from ballistic penetration and erosion events for $\mathrm{W}-\mathrm{Ni}-\mathrm{Co}$ and $\mathrm{W}-\mathrm{Ni}-\mathrm{Fe}$ kinetic energy rod projectiles penetrating steel target plates were observed to be highly cytotoxic to human epithelial A549 lung cells in culture after 48 hours of exposure. The aerosol consisted of micron-sized Fe particulates and nanoparticulate aggregates consisting of $\mathrm{W}, \mathrm{Ni}$ or $\mathrm{W}, \mathrm{Co}$, and some Fe, characterized by scanning electron microscopy and transmission electron microscopy, and using energy-dispersive (X-ray) spectrometry for elemental analysis and mapping. Cytotoxic assays of manufactured micron-sized and nanosized metal particulates of $\mathrm{W}, \mathrm{Ni}, \mathrm{Fe}$, and Co demonstrated that, consistent with many studies in the literature, only the nanoparticulate elements demonstrated measurable cytotoxicity. These results suggest the potential for very severe, short-term, human toxicity, in particular to the respiratory system on inhaling ballistic aerosols.
\end{abstract}

Keywords: cytotoxicity assays, ballistic penetration, metal aerosols, micron-nanoparticulate analysis, microstructure, microchemical, analysis

\section{Introduction}

It is now well established that ultrafine or nanoparticulates with a wide range of morphologies and chemistries exhibit varying degrees of respiratory toxicity as determined by their in vitro cytotoxicity in cell culture assays. ${ }^{1-4}$ Correspondingly, atmospheric particulates or aerosol compositions in excess of $1 \mu \mathrm{m}$ for the same dose do not usually exhibit any detectable cytotoxicity. ${ }^{1,3,5}$

A recent study by Machado et al of filter collections representing aerosol debris resulting from heavy alloy tungsten, kinetic energy rod projectiles penetrating steel plate arrays in steel enclosures demonstrated the induction of rapid and complete death of a human epithelial cell type in culture. ${ }^{6}$ This suggests that there may be a severe human toxicity potential for inhaled ballistic aerosol inside an armored vehicle penetrated by a variety of projectiles, particularly of tungsten heavy alloy rods into steel armor.

Earlier work by Guillmette et $\mathrm{al}^{7}$ addressed the potential health risks for depleted uranium aerosols, while Gold et $\mathrm{al}^{8}$ also examined aerosols inside an armored vehicle penetrated by tungsten heavy alloy projectiles. While Gold et $\mathrm{al}^{8}$ and Machado et $\mathrm{al}^{6}$ detected a variety of ultrafine (nanosized) and fine (micron-sized) particulates, only the work by Machado et al demonstrated severe respiratory health implications, although there was no clear indication of the specific role played by nanoparticulates in contrast with fine micron-sized particulates, or chemical speciation effects.
Correspondence: Brenda I Machado

Department of Metallurgical and Materials Engineering, The University of Texas at El Paso, El Paso, TX 79968, USA Tel +19156306404

Fax + I 9157478036

Email bimachado@miners.utep.edu 
Machado et al demonstrated a propensity for Fe particles (range 1.0-0.01 $\mu \mathrm{m}$ ) as well as smaller $\mathrm{W}$ particulates $(<1 \mu \mathrm{m})$. There was no indication of elemental mixing of the target and tungsten heavy alloy (Fe and W, respectively). ${ }^{6}$ Although the projectiles also contained about 8\% (weight) of either $\mathrm{Fe}$ and $\mathrm{Ni}$, or $\mathrm{Fe}$ and $\mathrm{Co}$, there was no significant evidence of these elements either in combined (or alloyed) form or as single-component nanoparticulates in the collected aerosol, even though the nanoparticulate fraction collected on the filters dominated the particle concentration.

In the present study, we performed cell culture assays using a human lung epithelial cell line for micron-sized and nanosized particles of $\mathrm{Fe}, \mathrm{W}, \mathrm{Ni}$, and Co after careful characterization by both scanning electron microscopy (SEM) and transmission electron microscopy (TEM). In addition, we performed energy-dispersive X-ray analysis and highresolution elemental mapping of previously collected aerosol particles scraped from collection filters in order to establish the elemental compositions (chemistries) for a wide distribution of collected particulates, particularly nanoparticulates, for comparison with the speciated particulates, by doing a comparison of the prior cell culture assay results ${ }^{6}$ with those for speciated particulates. Finally, we mixed speciated nanoparticulates (Fe/W, W/Ni, W/Co Fe/Ni, Fe/Co) and examined their cytotoxicity in contrast with the original filter assays, as well as the single-element particulates in the context of symbiotic effects for mixed chemistries, especially for the collected nanoparticulates.

\section{Materials and methods}

\section{Ballistic aerosol production methodology}

Figures 1 and 2 provide a fundamental overview of debris generation during the penetration and perforation of a kinetic energy rod into a steel target or targets. Beginning with Figure $1 \mathrm{~A}-\mathrm{C}$, the penetration process is illustrated schematically. As the kinetic energy rod, with initial length $l_{0}$ (Figure 1A), penetrates the target (Figure 1B), both the target and projectile erode, with target material effectively flowing backward (opposite to the projectile penetration direction) along with the erosion products from the penetrator, which is referred to as a rod erosion tube streaming from the head of the penetrating projectile rod. The target also erodes or excavates as a target erosion tube (in Figure 1C) whereupon perforation of the target as illustrated in Figure $1 \mathrm{C}$ produces a debris field consisting of aerosol particulates at the back of the target indicated by D in Figure 1C. Figure 1D and 1E illustrate this phenomenon for the penetration (and perforation) of a tungsten heavy alloy rod into a copper target. Figure 1D shows a half-section for the penetrated target, while Figure 1E illustrates a flash X-ray image for the eroded rod projectile exiting the target at $\mathrm{P}$. The $\mathrm{X}$-ray radiograph also captures the debris field production at the back of the target.

As described in detail by Pizaña et $\mathrm{al}^{9}$ and by Murr and Pizaña, ${ }^{10}$ the erosion of a steel target and penetrating kinetic energy rod as shown schematically in Figures $1 \mathrm{~B}$ and $1 \mathrm{C}$ occurs by solid-state flow of both the eroding projectile and the target by dynamic recrystallization. This produces a very small (submicron) grain size in both the rod erosion tube and target erosion tube in Figures 1B and 1C, respectively, which allows them to flow initially in the same direction toward the entrance surface. This feature is illustrated in the example of a single crystal (001)-oriented W kinetic energy rod penetrating a steel target in Figure 2. In this example, the dynamic recrystallization is particularly notable in the projectile because it in fact begins as a single crystal. In the degree of penetration shown in the half-section view of Figure 2, the rod erosion tube is observed to be a series of erosion planes flowing one over the other as a result of dynamic recrystallization grain sizes which are too small to observe. The target erosion tube is also a narrow flow zone, and when the rod erosion tube flows over the target erosion tube, some mixing occurs, even alloying the Fe target with the $\mathrm{W}$ projectile debris tube. Pizaña et al observed $\mathrm{Fe}-\mathrm{W}$ or $\mathrm{Fe}_{\mathrm{x}} \mathrm{W}$ phase regions in the mixing of the rod erosion tube and target erosion tube (Figure 2) using energy-dispersive X-ray (or energy-dispersive spectrometry) mapping in the SEM. Consequently, aerosol particulates (especially nanoparticulates) were observed as speciated $\mathrm{Fe}$ (from the target), $\mathrm{W}$ (from the projectile) and $\mathrm{Fe}_{\mathrm{x}} \mathrm{W}$ alloy as a consequence of projectile/target mixing.

In our previous work, ${ }^{6}$ all debris particulates (D in Figure 1C) were collected systematically on impacted filters which allowed the size distributions to be controlled, although the large size distributions always contained the complete range of nanoparticulates along with larger particulates.

\section{Particulate characterization}

We selected a range of commercially manufactured micron-sized and nanosized particles of $\mathrm{Fe}, \mathrm{W}, \mathrm{Ni}$, and $\mathrm{Co}$ from commercial sources in order to emulate possible elemental speciation for two tungsten heavy alloy rod compositions, ie, 91\% (by weight) W, $5.6 \% \mathrm{Ni}, 1.4 \% \mathrm{Fe}$, and $92 \% \mathrm{~W}, 6 \% \mathrm{Ni}$, and $2 \% \mathrm{Co}$. The micronsized (powder) particulates were observed directly in a Hitachi S-4800 field-emission scanning electron microscope (FESEM) fitted with an EDAX energy-dispersive spectrometry system by adhering them to a sampling platform. The nanosized powders were also examined in the FESEM and in a Hitachi H-9500 
A

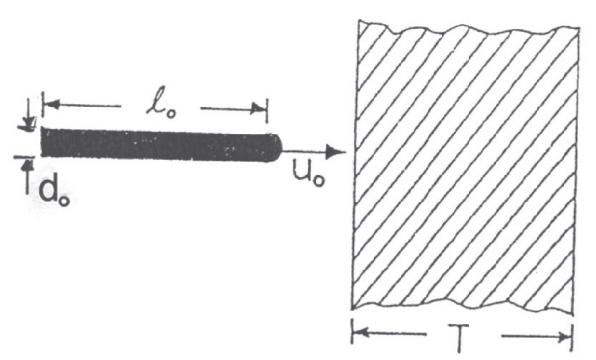

B

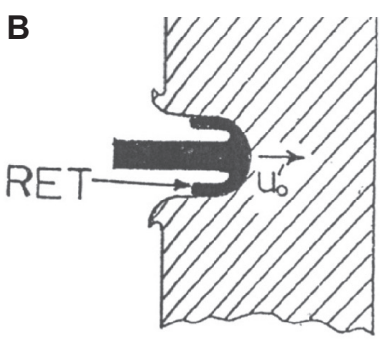

C

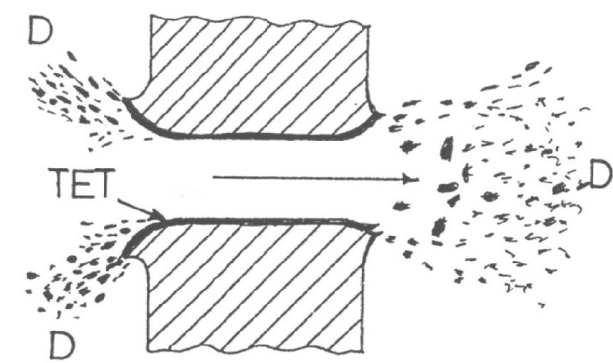

E

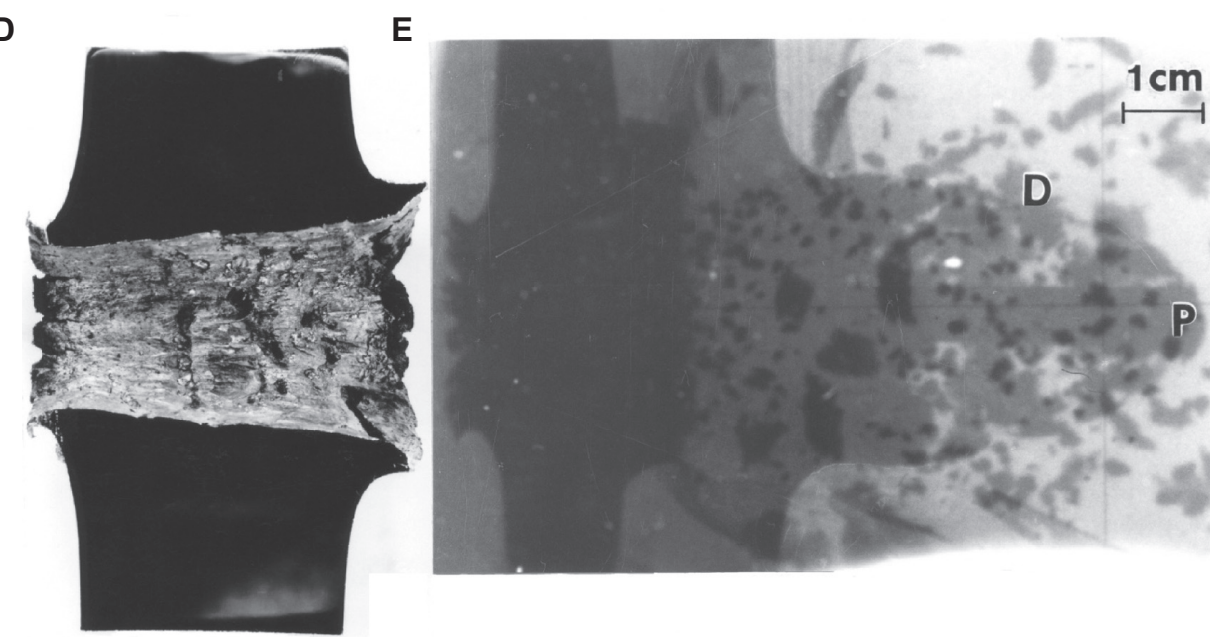

Figure I Ballistic projectile, kinetic energy rod penetration of a target plate. A) Rod of length, $I_{0}$, impacting a plate at a velocity of $u_{0}$. B) Penetrating rod, eroding at its head to form a rod erosion tube (RET) around the projectile head at reduced velocity $\mathrm{u}_{0}{ }^{\prime}$. C) Perforated plate which has formed a target erosion tube (TET) similar to the rod erosion tube in B. Ballistic debris field in the front and rear of the impacted target (D). D) Polished cross-section of a $3.5 \mathrm{~cm} C \mathrm{Cu}$ target plate penetrated by a heavy alloy tungsten rod. E) Flash X-ray radiograph showing heavy alloy tungsten rod penetrating the Cu target in (D). The eroded projectile head exiting the target is shown at $P$. The debris field behind target plate is shown at $D$.

TEM operating at $300 \mathrm{kV}$ accelerating potential, employing an EDAX energy-dispersive spectrometry system. The TEM also employed a digital imaging camera which allowed direct magnifications in excess of $10,000,000 \times$. The manufactured nanoparticulate powders were sprinkled onto a $\mathrm{SiO} /$ Formvarcoated $\mathrm{Cu}$ (200 mesh) TEM grid (3 mm diameter) and then sandwiched with another grid on top to contain the powder.

\section{Cell culture viability assays}

In vitro cytotoxicity assays were performed for the commercial micron-sized and nanosized particulates as well on the filter-collected ballistic particulates using a direct contact cell culture methodology as originally described by Garza et $\mathrm{al}^{11}$ and Soto et al. These assays used an immortalized A549 human lung epithelial cell line which provides an effective in vitro lung cell model which has been widely adopted as a human lung cell model. The cell line was obtained by the American Tissue Culture Collection from the carcinomatous lung tissue of a 58-year-old Caucasian male. The A549 cells were cultured in 12-well plates and then exposed for 48 hours (standard time for acute exposures). After the exposure period, they were transferred into a 96-well flat bottom plate to assess viability via the MTS assay. This colorimetric assay assesses relative viability as a function of color, which is directly proportional to the amount of cells available to convert the substrate into a color product. Finally, the absorbance was recorded at $490 \mathrm{~nm}$ using a spectrophotometer reader. 


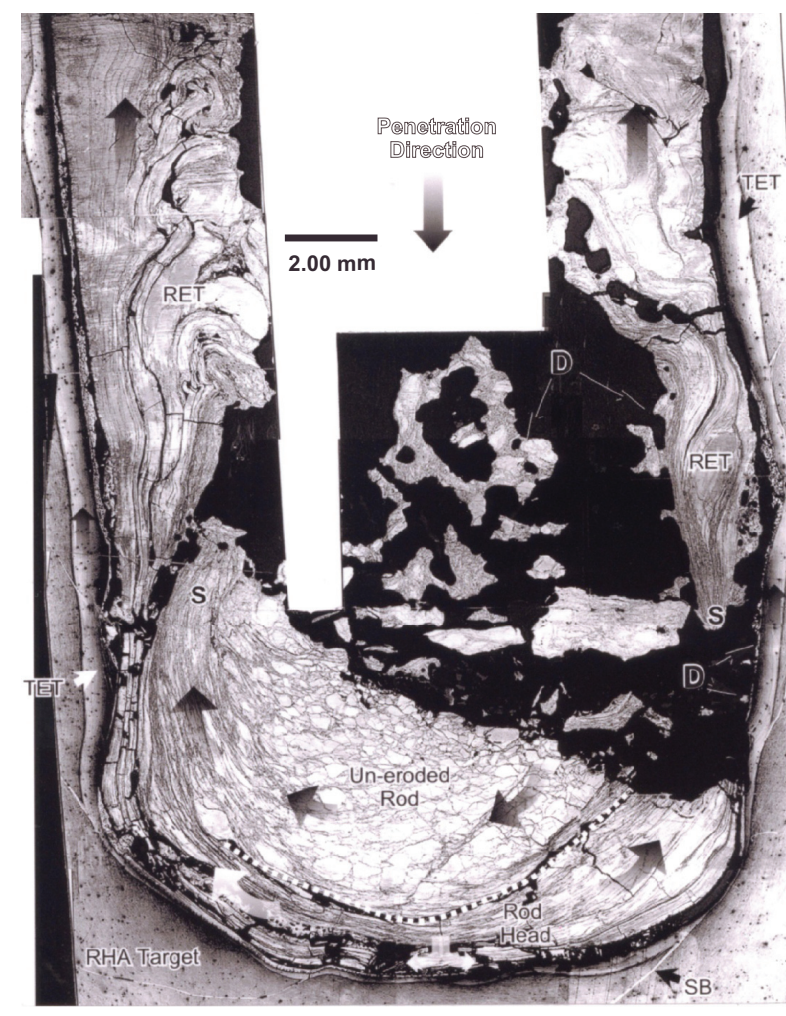

Figure 2 Section view of polished and etched W (kinetic energy) rod penetrating a steel target plate at an impact velocity ( $\mathrm{u}_{\circ}$ in Figure I) of $1.3 \mathrm{~km} / \mathrm{sec}$. Note target erosion tube (TET) and rod erosion tube (RET) zones which flow in the direction opposite to the penetration direction. Debri fragments are denoted as D. Also note recrystallization of the head of the single-crystal W rod, and erosive flow at the head. Abbreviations: SB, shear bands; RHA, rolled homogeneous armor; S, erosion tube initiation zones.

\section{Results and discussion}

\section{Comparison of manufactured particulate} microstructures with reference to filter-collected ballistic particulates

Figures 3 and 4 provide a reference basis for the filtercollected tungsten heavy alloy rod-Fe target debris particles for a $\mathrm{W}-\mathrm{Ni}-\mathrm{Fe}$ projectile penetrating a series of $10 \mathrm{Fe}$ target plates $0.63 \mathrm{~cm}$ thick and spaced $1.25 \mathrm{~cm}$ apart at an initial impact velocity of $1.2 \mathrm{~km} / \mathrm{sec}$ (Figure 1A). ${ }^{6}$ Figure 3 shows a typical FESEM view of the particulates collected on a filter along with the energy-dispersive spectra showing predominantly Fe, with $\mathrm{W}, \mathrm{C}$, and $\mathrm{O}$. The $\mathrm{C}$ peak along with the $\mathrm{K}$, for example, may represent intermixed combustion products, including soot-related nanoparticulates and coatings of other particulates related to the rod propellant composed primarily of nitrocellulose, nitroglycerin, $\mathrm{Ba}\left(\mathrm{NO}_{3}\right)_{2}, \mathrm{KHO}_{3}$, ethyl centralite, and graphite. The larger spherical particulates $(\leq 1.5 \mu \mathrm{m})$ are primarily Fe, presumably representing Fe target debris. Note that particulates in the smaller range are aggregated. Correspondingly, Figure 4 shows a TEM view for the same filter-collected ballistic debris particulates scraped onto a

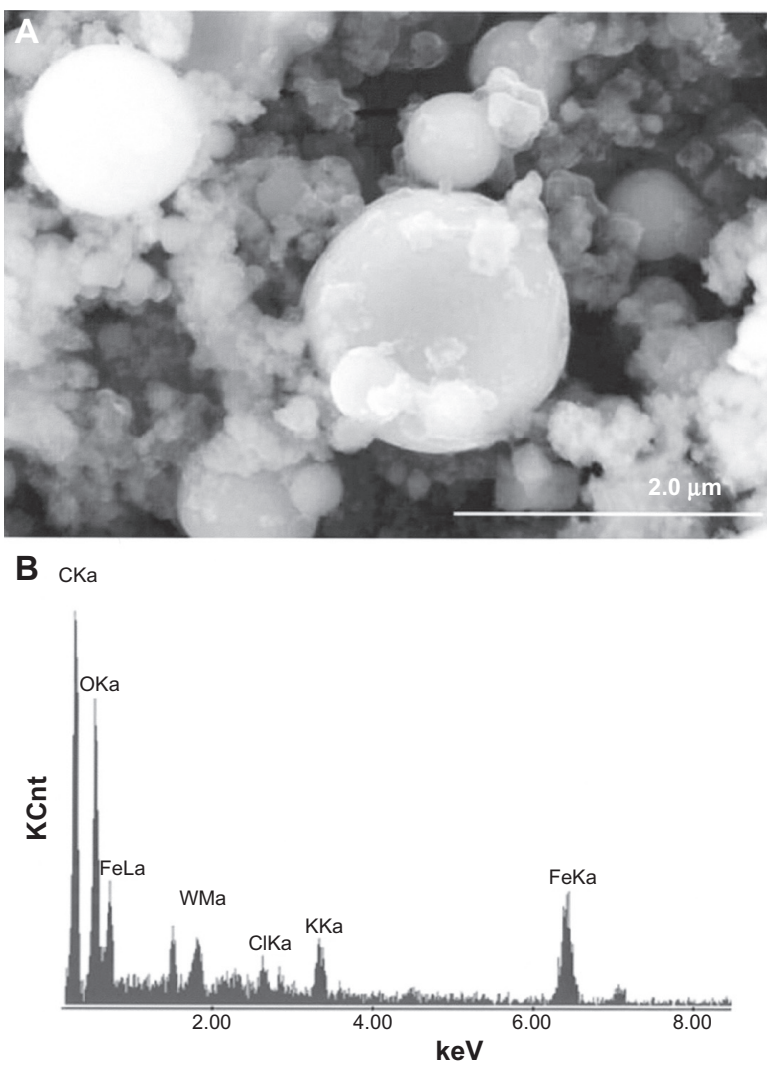

Figure 3 Field-emission scanning electron microscope view of collected ballistic (impact) debris (A), and the corresponding energy-dispersive spectrum (B): W-Ni-Fe.

coated grid sandwich. The nanosized spherical particulates as in Figure 3A are also generally Fe-rich, while the surrounding, diffuse aggregates are composed of metal or alloy nanoparticles bound by carbonaceous material. There is often a carbonaceous layer surrounding the larger, Fe-rich particulates, but this layer often appears to be a complex metal alloy. In addition to the dominant Fe spectra and notable $\mathrm{W}$, there is a small Ni peak in Figure 4B, but the specific distribution of these elements within the particulates and aggregates is often unclear.

Figure 5 shows a bright-field TEM image and an elemental mapping sequence for $\mathrm{W}-\mathrm{Ni}-\mathrm{Fe}$ ballistic debris similar to Figure 4, whereby the larger particles in Figure 5 are composed of $\mathrm{Fe}$ and some $\mathrm{Ni}$, while the very fine, aggregated nanoparticle debris is composed primarily of $\mathrm{W}$ and $\mathrm{Ni}$. Figure 6 shows for comparison an elemental mapping sequence for $\mathrm{W}-\mathrm{Ni}-\mathrm{Co}$ ballistic debris also examined in the TEM. The irregular, small nanoparticulate background is observed to be primarily W-rich or nanoparticulate $\mathrm{W}$ with more irregular morphology. There is also some Co associated with the Ni region, which probably represents the approximately $6 \% \mathrm{Ni}$ and $2 \%$ Co alloy nanoparticulates.

Figure 6 illustrates that the larger, spherical, or faceted nanoparticles (about $500 \mathrm{~nm}$ ) are $\mathrm{Ni}-\mathrm{Co}$ (with varying ratios 


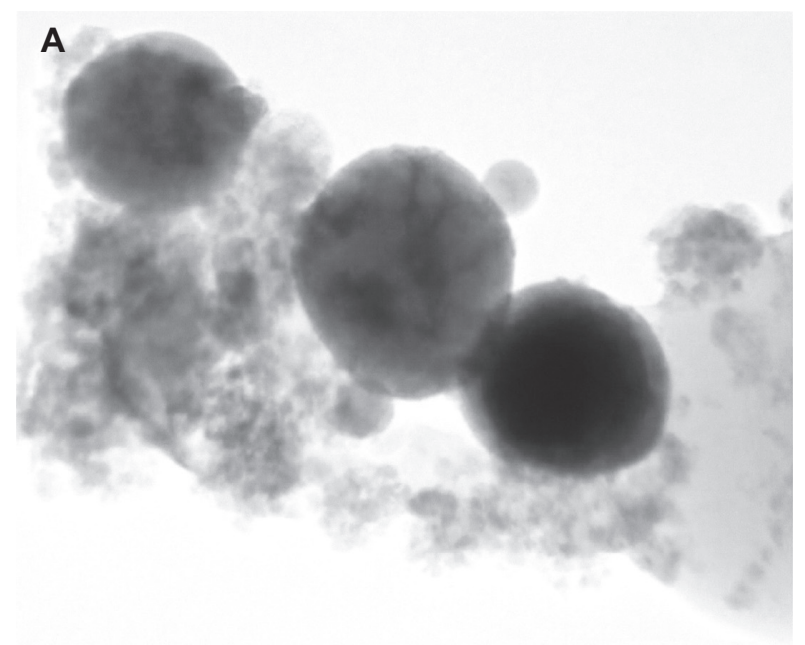

$100 \mathrm{~nm}$

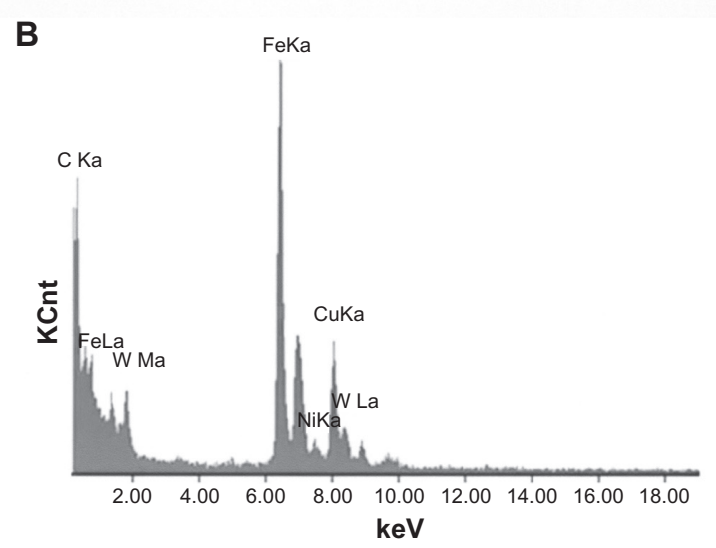

Figure 4 Transmission electron microscopy image of collected impact debris as in Figure $3 \mathbf{A}$, and corresponding energy-dispersive spectrometry spectrum B: $\mathrm{W}-\mathrm{Ni}-\mathrm{Fe}$. Note the sandwich is composed of coated $\mathrm{Cu}$ grids. The $\mathrm{Cu}$ peak $(K \alpha)$ arises from the grid. Note small Ni peak.

of $\mathrm{Ni}$ and $\mathrm{Co}$ ) or $\mathrm{Ni}-\mathrm{Fe}-\mathrm{Co}$ compositions. The upper right particle in Figure 6A appears to be enclosed by a ring-like zone composed of $\mathrm{Ni}-\mathrm{Fe}-\mathrm{Co}$ with a lower concentration of W. Consequently, the larger, spherical micron-sized particulates as shown in the FESEM view of Figure 3A appear to be Fe or Fe-rich, while the nanosized spherical particulates in the TEM views in Figure 6 are alloy mixtures of Fe-Ni-Co or $\mathrm{Ni}-\mathrm{Fe}$. The smallest, aggregated nanoparticulate regimes are irregular, elemental W ( $\leq 50 \mathrm{~nm}$ ), along with some $\mathrm{Ni}-\mathrm{Co}$ or $\mathrm{Ni}-\mathrm{Fe}$ alloy nanoparticulates representing the projectile matrices, respectively, although some of this aggregated nanoparticulate debris may be Ni-rich. The metal-rich ring surrounding a spherical particle in Figure 6A may also represent matter created by metal or alloy vapor in the same way that some metal particulates, particularly Fe, appear to be coated with carbonaceous matter. ${ }^{8}$ The lower right elemental map shows $\mathrm{Ni}, \mathrm{Fe}$, and very strong $\mathrm{Co}$ in the spherical-like particles, while the $\mathrm{W}$ is, as noted, prominent
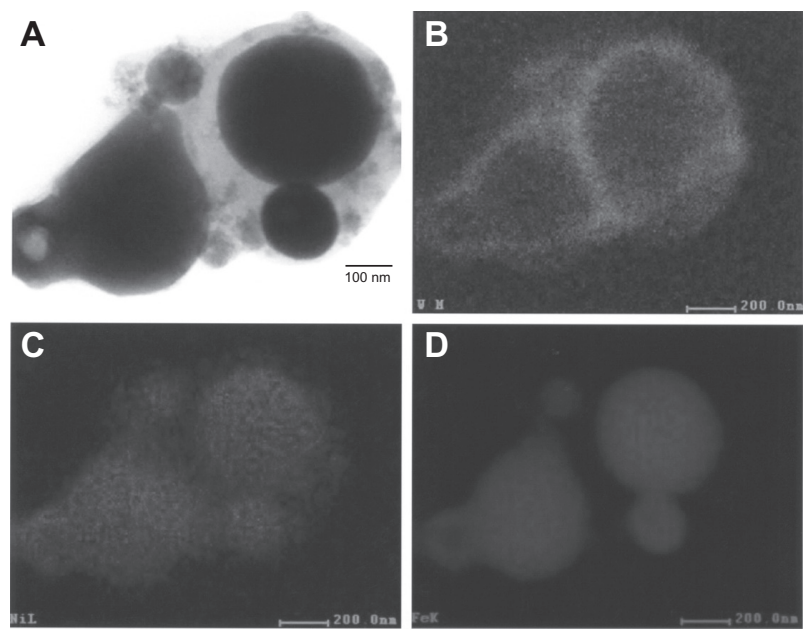

Figure 5 Transmission electron microscopy X-ray (energy-dispersive spectrometry) mapping sequence for $\mathrm{W}-\mathrm{Ni}-\mathrm{Fe}$ ballistic debris sample. A) Bright-filled image of aggregated particulates. B) W map, C) Ni map, and D) Fe map.

in the nanodebris area to the left, along with $\mathrm{Ni}$ as shown in the first elemental map for Ni.

In comparison with the ballistic debris collections examined in Figures 3-6, the manufactured particulate powders exhibited similar morphologies. These are illustrated typically in the sequence of FESEM and TEM observations shown in Figures 7-15. Figures 7 and 8 show two varieties of micron-sized $\mathrm{Fe}$ and $\mathrm{W}$ at different magnifications. The $\mathrm{Fe}$ particulates in Figure 7A and 7C are recognizably aggregated in the manufacturing process. The Fe particles are generally spherical, while the $\mathrm{W}$ particles are notably faceted single crystals.

Figures 9 and 10 compare nanoparticulate Fe and W powders, respectively, in the TEM, while each image also contains an FESEM insert. These particulates are also aggregated but contain a high fraction of very small particulates $(5-50 \mathrm{~nm})$ in contrast to a larger range of micron-sized spherical particles, creating a broad nanosized particle distribution with a smaller distribution of micron-sized particles (1-3 $\mu \mathrm{m}$ diameter), creating a skewed, bimodal size distribution toward the small nanoparticulate range.

Figure 1 compares the micron-sized or near-micron-sized powders for $\mathrm{Ni}$ and $\mathrm{Co}$, respectively. In contrast to the micron-sized Fe and $\mathrm{W}$ powders in Figures 7 and 8, the generally aggregated $\mathrm{Ni}$ and $\mathrm{Co}$ powders are generally $\leq 1 \mu \mathrm{m}$, in contrast with the $\mathrm{Fe}$ and $\mathrm{W}$ powder particle sizes, which include particle sizes $\leq 3 \mu \mathrm{m}$. Nonetheless, these particulates exhibit a very narrow size distribution averaging roughly $0.8 \mu \mathrm{m}$.

Figures 12-14 compare the nanosized Ni and Co powders. The aggregated Ni particulates in Figure 12 exhibit growth 

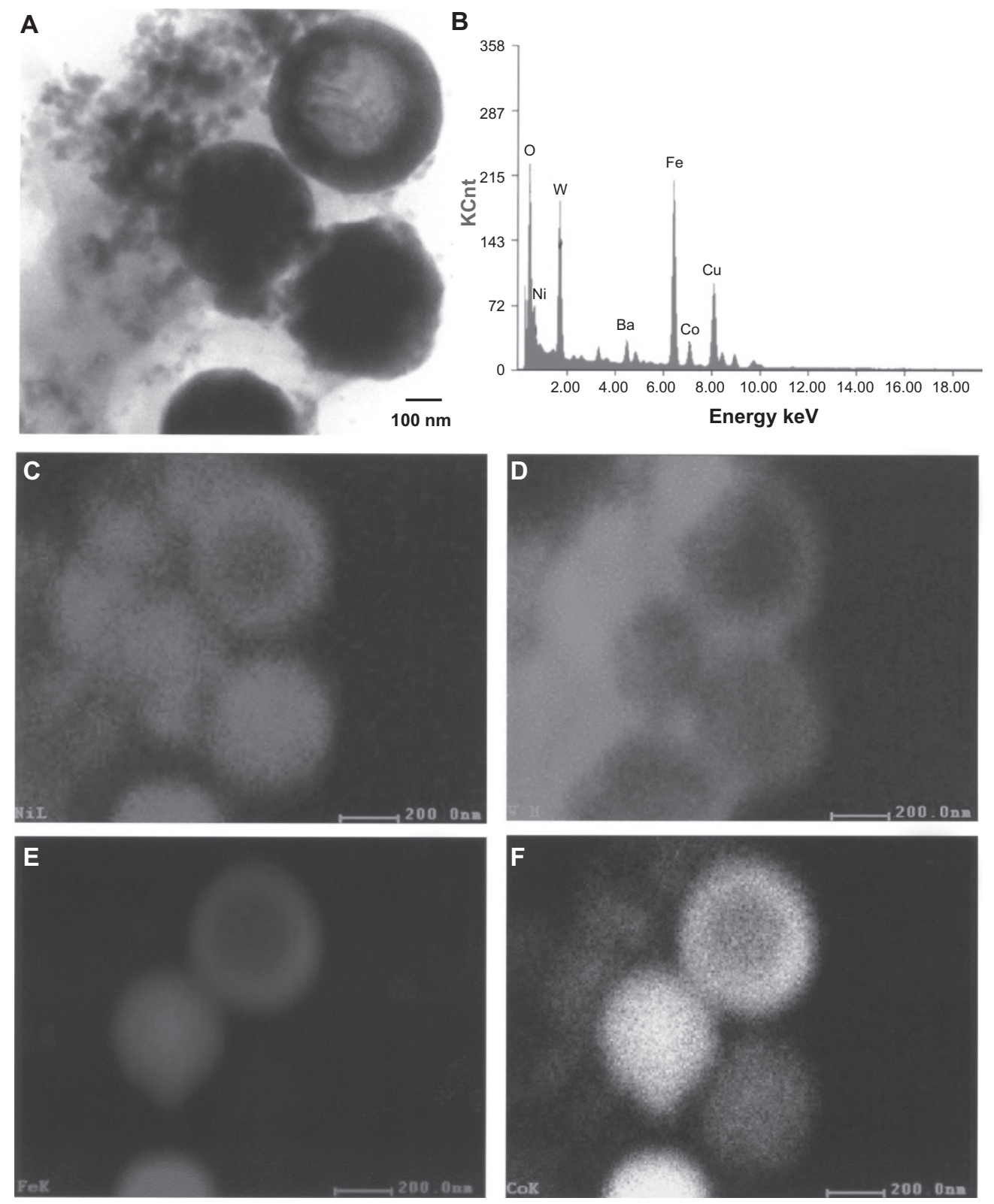

Figure 6 Transmission electron microscopy X-ray (energy-dispersive spectrometry) mapping sequence for W-Ni-Co ballistic debris sample. A) Bright-field image of aggregated particulates, B) energy-dispersive spectrometry spectrum of (A), C) Ni map, D) W map, E) Fe map, and F) Co map.

twins in otherwise perfect single-crystal particles. The FESEM insert in Figure 12 shows the aggregated, dominant nanoparticle size distribution. Figure 13 compares the nanoparticulate $\mathrm{Ni}$ in bright-field and dark-field (Figures 13A and 13B) imaging utilizing a small portion of the face-centered cubic selected-area electron diffraction pattern insert. The dark-field image confirms the single-crystal particulate nature and also illustrates their size and morphology more definitively. Correspondingly, Figure 14 shows a TEM image for the Co nanoparticulates with an FESEM image insert. These nanoparticulates are also aggregated in a fashion similar to the micron-sized particulates shown in Figure 11B.
Figure 15 shows a high-resolution TEM image for an aggregate of Co nanoparticulates which confirms the singlecrystal, sintered particle nature. There is also evidence for an oxide layer enclosing the particles, while the Moire fringe pattern illustrates the extent of the Co crystal structure within an amorphous oxide layer approximately $3 \mathrm{~nm}$ thick.

We measured the particle size distributions for the manufactured micron-sized and nanosized powders illustrated comparatively in Figures 7-15, and noted the size range or width of the size distribution. In addition, we measured the average size for each size range of particles. These measurements along with other particle properties are listed in Table 1. 

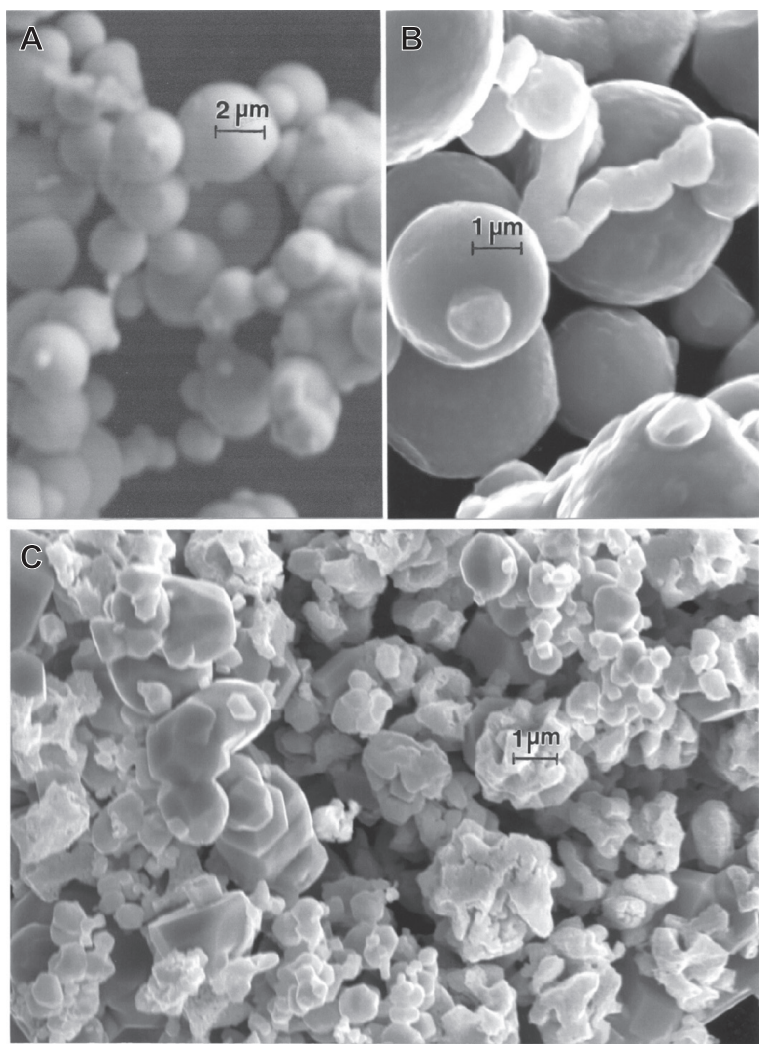

Figure 7 Field-emission scanning electron microscope images of micron-sized $\mathrm{Fe}$ and $\mathrm{W}$ powders. A Fe, B Fe, and $\mathbf{C} \mathrm{W}$.
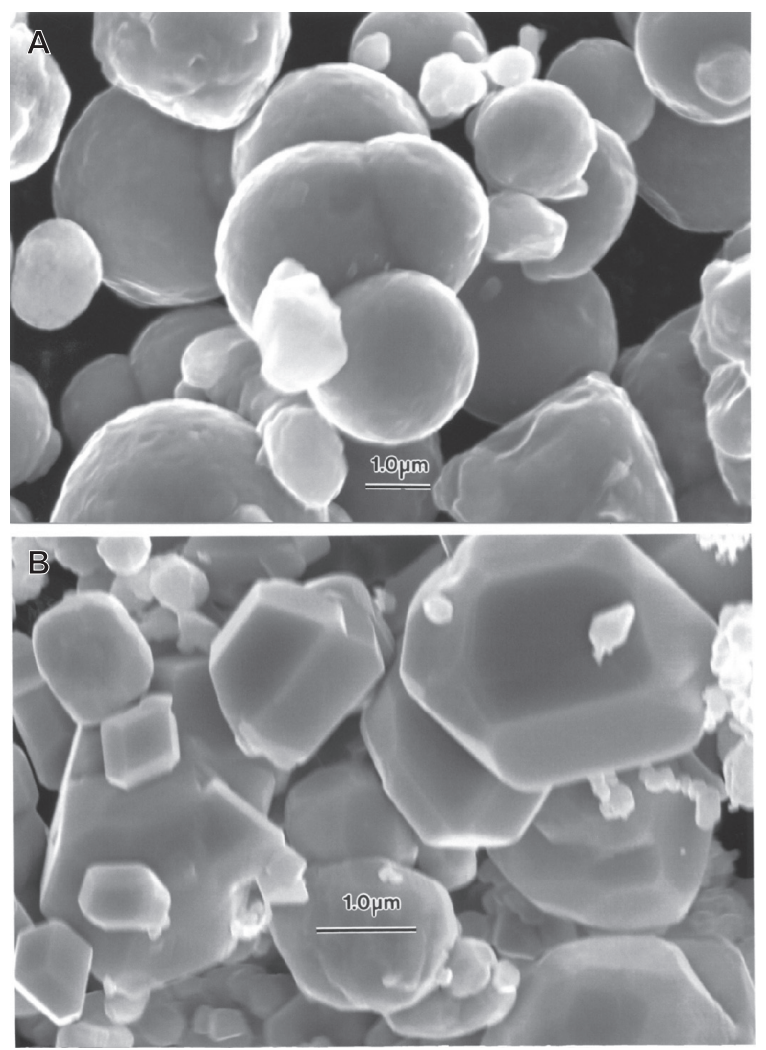

Figure 8 Magnified field-emission scanning electron microscope images for micronsize Fe and W powders. A Fe and $\mathbf{B}$ W.



Figure 9 Transmission electron microscopy image for nano-Fe powder with field-emission scanning electron microscope image insert showing nanoparticulate aggregation.

\section{Viability assays and assay comparisons}

In vitro assays in A549 human epithelial cell cultures for 48 hours for several assay groups representing ballistic debris collections reproduced from prior work by Machado et $\mathrm{al}^{8}$ are shown in Figure 16A and 16B. These assays demonstrate



Figure 10 Transmission electron microscopy image for nano-W powder with field-emission scanning electron microscope image insert showing nanoparticulate aggregation. 


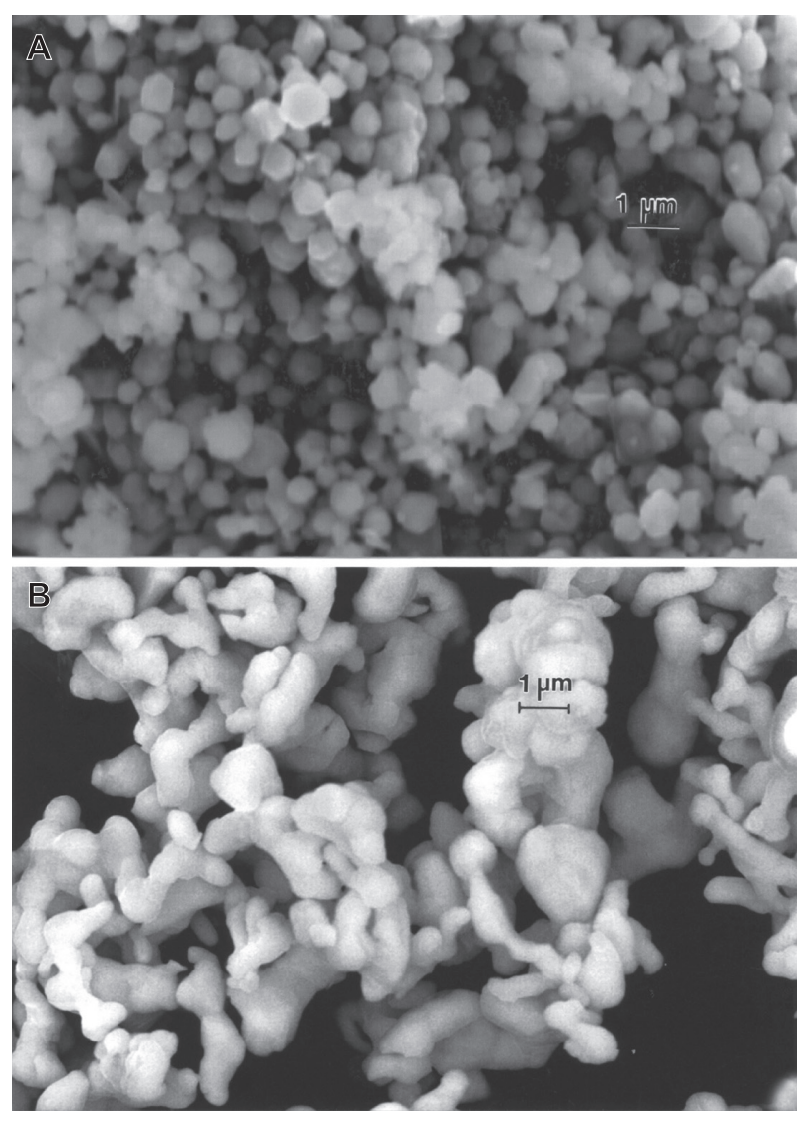

Figure I I Field-emission scanning electron microscope images for micron-sized $\mathrm{Ni} \mathbf{A}$ and $\mathrm{Co} \mathbf{B}$ powders.

that the A549 cells were killed so extensively that only aggregates of the nanoparticulates taken up by the cells remained, particularly for samples 11 and 3 .

Figures $16 \mathrm{C}, 16 \mathrm{E}$, and $16 \mathrm{G}$ show, in comparison with Figures 16A and 16B, that the single component (elemental) metal nanoparticulates (Table 1) exhibit notable cytotoxicity, which is not as significant as for the mixture of ballistic debris particulates shown in Figures 16A and 16B, especially for low concentrations in culture as shown in Figure 16G. There is a slight dominance of cytotoxic response for $\mathrm{Fe}$ and W nanoparticulates (Table 1), but this was not statistically significant. In contrast, Figures 16D, 16F, and 16H show that, for varying concentrations of micron-sized metal particulates in culture, there is no notable cytotoxicity as measured by cell viability. However, the consistent slight (albeit insignificant) decline in viability for Ni may reflect the fact that it is at the upper nanosized range, and the smallest sized micron powder (Table 1).

Inhaled particulates (including coarse nanoparticles $<1 \mu \mathrm{m}$ ) initially encounter mucociliary clearance by the bronchial epithelial cells which moves the larger particles $(>1 \mu \mathrm{m})$ towards the upper respiratory tract. However, the

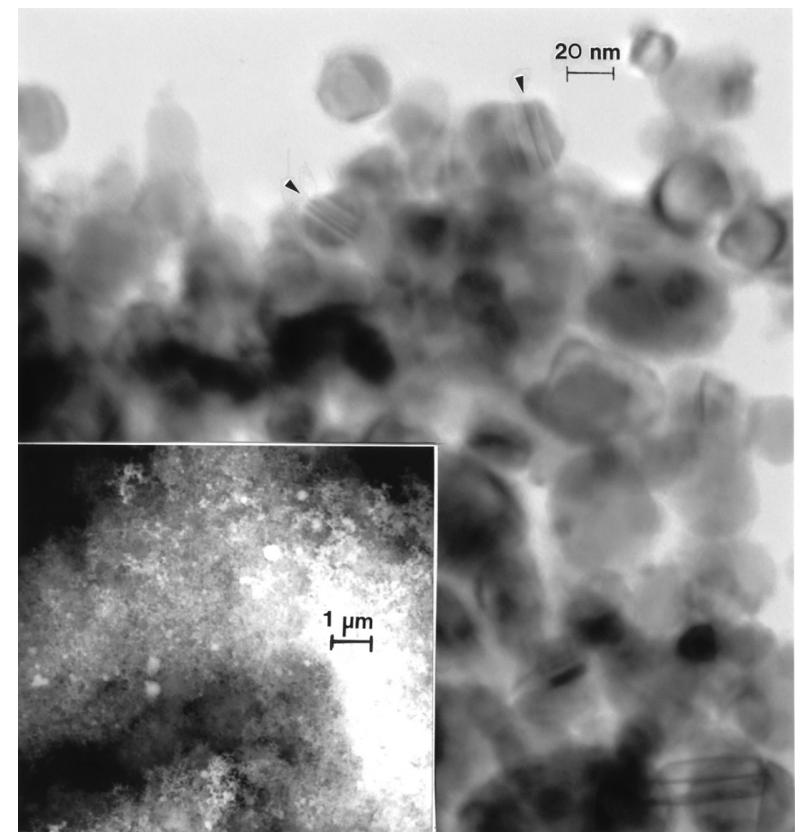

Figure 12 Transmission electron microscopy image for nano-Ni powder with fieldemission scanning electron microscope insert showing nanoparticulate aggregation. The features noted by arrows are microstructural twins in the particles.

true nanoparticles $(<1 \mu \mathrm{m})$ migrate to the alveoli where phagocytes and other cells with phagocytic ability work to arrest them. However, with phagocytic impairment, or for nanoparticles $<100 \mathrm{~nm}$ which are not readily phagocytosed, nanoparticles can accumulate and even aggregate to create oxidative stress and inflammation. ${ }^{12}$ This can lead to various diseases, in which inflammation plays a major role, eg, in coronary heart disease and airway diseases, such as asthma and chronic obstructive pulmonary disease. A prominent mechanism responsible for the variety of nanoparticle toxicities assumes a shift in the redox balance of the cells towards oxidation as a consequence of the formation of reactive oxygen species which can, in the longer term, lead to DNA damage.${ }^{13}$ In addition to oxidative stress, some nanoparticles can enhance the expression of specific viral receptors and lead to severe inflammation when exposed to viral infections, while other nanoparticles can decrease the expression of certain viral and bacterial receptors which lowers the resistance to some types of micro-organisms. ${ }^{14}$

While the in vitro cell culture results for varying concentrations of elemental metal nanoparticulates $(\mathrm{Fe}, \mathrm{W}, \mathrm{Ni}, \mathrm{Co})$ shown in Figures $16 \mathrm{C}, 16 \mathrm{E}$, and $16 \mathrm{G}$ are not as significant as those in Figure 16B, the lowest concentration in culture (Figure 16G) is comparable with Figure 16A, except for the Ni. Figures $16 \mathrm{C}-\mathrm{H}$ illustrate that, consistent with many prior studies, ${ }^{1,3,5}$ there is a measurably greater cytotoxic in vitro response to the nanosized metal powders in contrast to the 


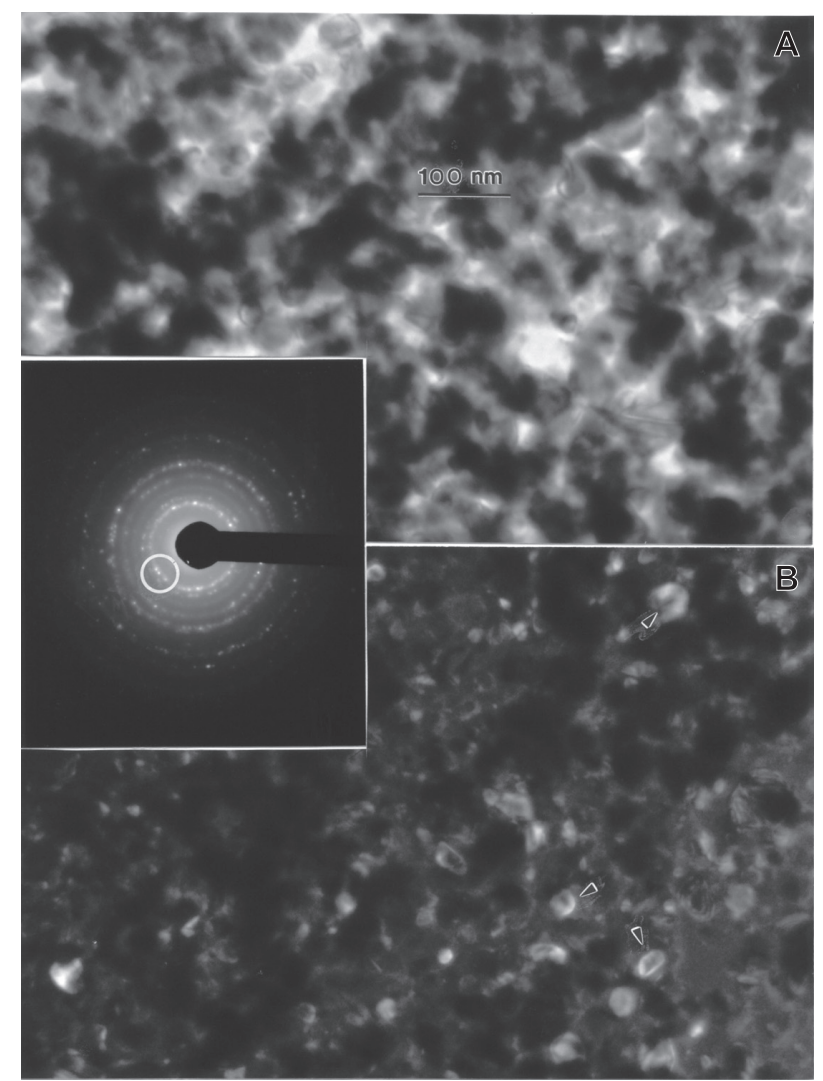

Figure 13 Transmission electron microscopy bright-field A) and dark-field B) sequence for nano-Ni powder utilizing selected diffraction spots from the selected-area electron diffraction pattern insert (circle). Arrows in B show diffracting nanoparticles.

micron-sized powders, although Oberdörster et al have concluded that aggregated nanoparticles are not as toxic as smaller concentrations of single particles. ${ }^{12}$ Nonetheless, because essentially the entire ballistic aerosol regime, as well as the elemental nanoparticles, are aggregated (Figures 3-15), this finding does not detract from the cytotoxicity demonstrated in Figure 16. In addition, Murr et $\mathrm{al}^{2}$ have shown that a wide range of aggregated nanoparticulate species are noticeably cytotoxic, including a wide range of metal oxides and nanosoots.

In order to investigate the potential cytotoxic synergism of the rod alloys or mixtures of nanoparticle elements, cell culture studies identical to those shown in Figure 16 were conducted for mixtures of both the micron-sized powders and the nanosized powders, ie, $\mathrm{Fe}+\mathrm{W}, \mathrm{Fe}+\mathrm{Co}$, $\mathrm{Fe}+\mathrm{Ni}$ in 50/50 mixtures in culture at concentrations of $10 \mu \mathrm{g} / \mathrm{mL}, 5 \mu \mathrm{g} / \mathrm{mL}$, and $2.5 \mu \mathrm{g} / \mathrm{mL}$ (data not shown). The micron-sized powder particle mixtures showed no cytotoxic response, consistent with the single-component powders in Figures 16D, 16F, and 16H. There was a small but statistically insignificant cell viability reduction for the $\mathrm{Fe}+\mathrm{Co}$ nanoparticulate mixture, leading us to the conclusion

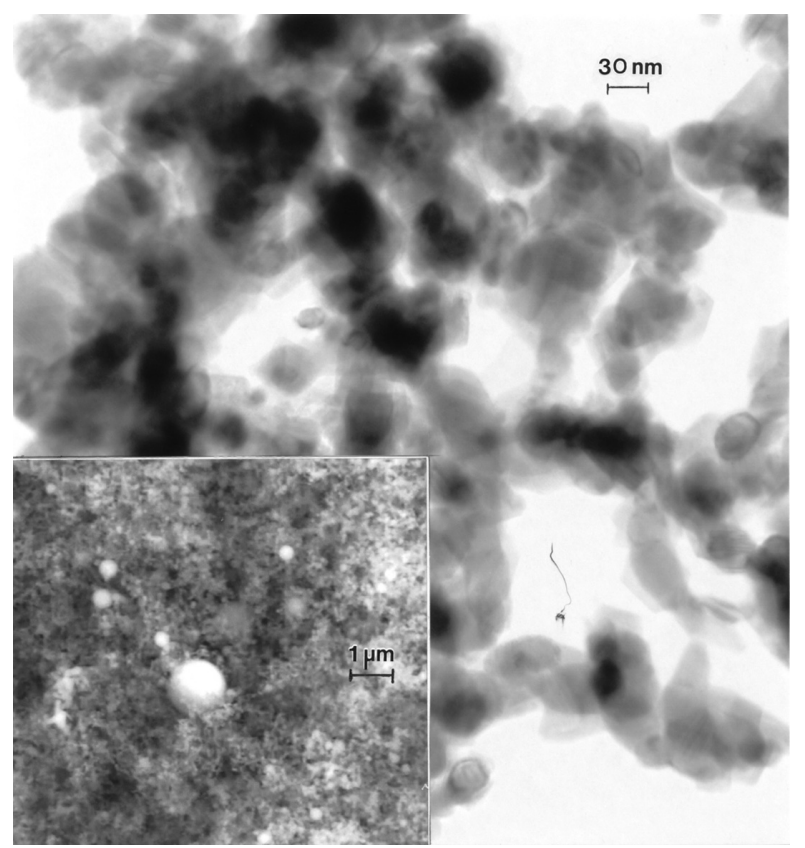

Figure 14 Transmission electron microscopy image for nano-Co powder with fieldemission scanning electron microscope insert showing nanoparticulate aggregation.

that elemental nanoparticulate synergism is apparently not an important contributor to the cytotoxic behavior observed for the ballistic aerosol in Figures 16A and 16B.

Figures 5 and 6 have demonstrated the propensity for W and Ni nanoparticulate aggregates, especially elemental

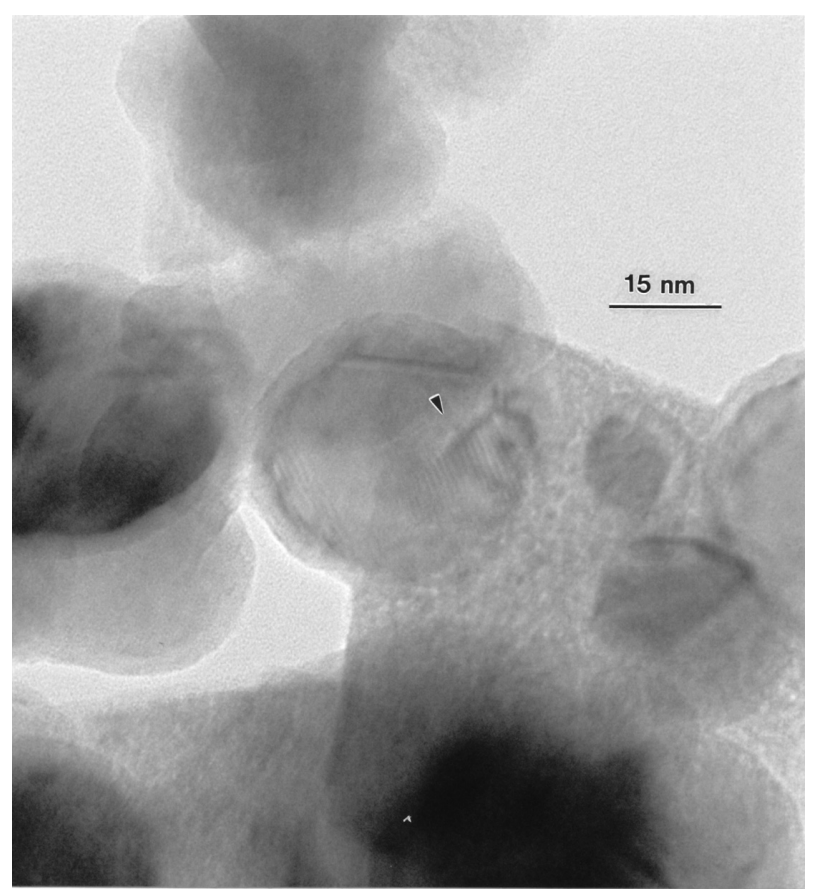

Figure 15 High-resolution transmission electron microscopy image for nanoCo powder aggregates showing Moire fringe pattern with $1.3 \mathrm{~nm}$ fringe spacing (arrow). 
Relative viability of A549 cells

collected aerosol particulates

A

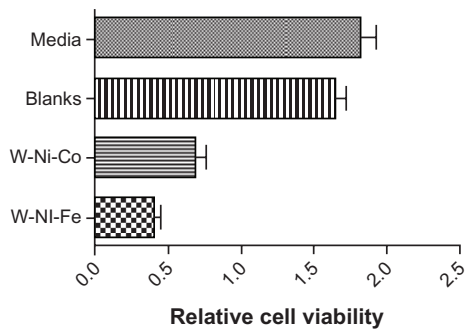

C

Acute exposure to $10 \mu \mathrm{g} / \mathrm{mL}$ of nano $(\mathrm{nm})$ particles

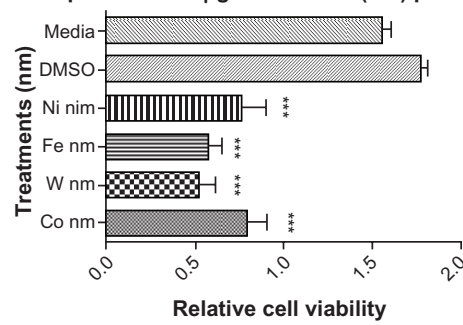

E

Acute exposure to $5 \mu \mathrm{g} / \mathrm{mL}$ of nano $(\mathrm{nm})$ particles

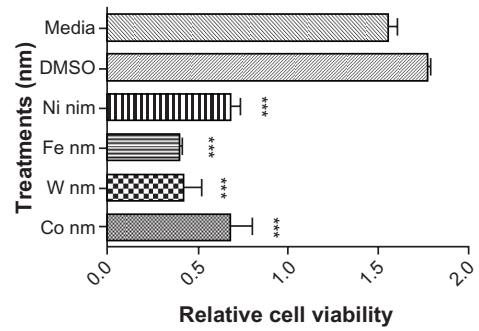

G

Acute exposure to $2.5 \mu \mathrm{g} / \mathrm{mL}$ of nano $(\mathrm{nm})$ particles



B

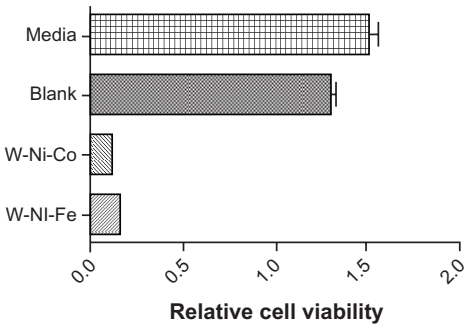

D

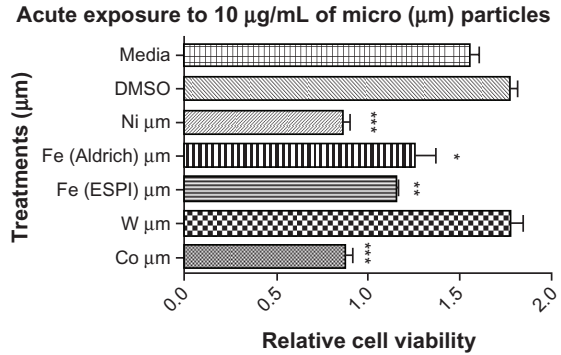

$\mathbf{F}$

Acute exposure to $5 \mu \mathrm{g} / \mathrm{mL}$ of micro $(\mu \mathrm{m})$ particles

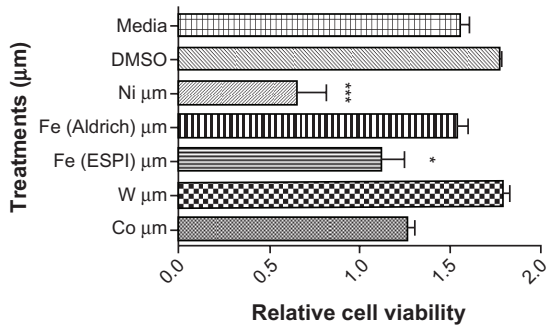

H

Acute exposure to $2.5 \mu \mathrm{g} / \mathrm{mL}$ of micro $(\mu \mathrm{m})$ particles

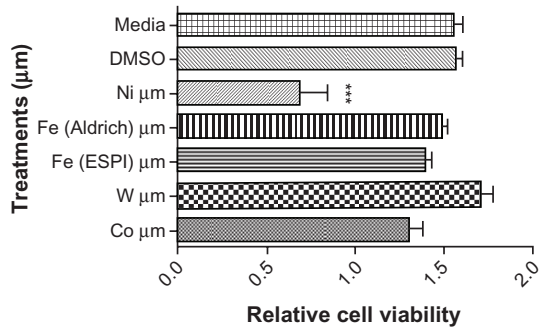

Figure 16 Comparative cytotoxicities (as relative A549 epithelial cell viability). A) and B) show collections for four separate ballistic events, ie, two for W-Ni-Fe and two for $\mathrm{W}-\mathrm{Ni}$-Co KE rods penetrating Fe target plates. C) and D) compare nanosized and micron-sized powders at concentrations in culture of $\mathrm{I} 0 \mu \mathrm{gg} / \mathrm{mL}$. E) and F) compare nanosized and micron-sized powders at concentrations in culture of $5 \mu \mathrm{g} / \mathrm{mL}$. G) and $\mathbf{H}$ ) compare nanosized and micron-sized powders at concentrations of $2.5 \mu \mathrm{g} / \mathrm{mL}$. All cell culture assays $\mathbf{A}$ ) to $\mathbf{H}$ ) are compared with culture media as a control. $\mathbf{A}$ ) and $\mathbf{B}$ ) also show blank filter culture as a control. $\mathbf{C}$ ) to $\mathbf{H}$ ) show dimethyl sulfoxide as a control.

Notes: $* P<0.5 ; * * P<0.0015 ; * * * P<0.0001$

Abbreviations: DMSO, Dimethyl Sulfoxide; ESPI, high purity metals manufacturing company.

nanoparticulates in the range of 5 to $10 \mathrm{~nm}$, with some elemental mixing especially in larger nanoparticles, possibly as a result of projectile erosion and mixing with the Fe target erosion regime by dynamic recrystallization as illustrated in Figure 2. On considering Figures 5 and 6 in comparison with the results of Figure 16A and 16B, and Figure 16C, 16E, and 16G along with Figure 16D, 16F, and $16 \mathrm{H}$, there seems to be compelling evidence for a significant cytotoxic response for $\mathrm{W}, \mathrm{Fe}, \mathrm{Ni}$, and Co nanoparticulates in contrast with micron-sized particulates of these elements. Consequently, on perusing Figures 4-6 retrospectively, it would appear that the ballistic debris cytotoxicity shown in Figure 16A and 16B results from the smallest nanoparticulate aggregates of $\mathrm{W}$, or possibly Ni-Co or Ni-rich nanoparticles $<10 \mathrm{~nm}$. This conclusion also points to the prospect that it is primarily the tungsten heavy alloy projectile which exhibits or induces the significant cytotoxicity for ballistic aerosol debris. 
Table I Experimental (manufactured) powder properties

\begin{tabular}{|c|c|c|c|c|c|}
\hline Element & $\begin{array}{l}\text { Size range } \\
(\mu \mathrm{m})\end{array}$ & $\begin{array}{l}\text { Mean size } \\
(\mu \mathrm{m})\end{array}$ & $\begin{array}{l}\text { Crystal } \\
\text { structure }\end{array}$ & $\begin{array}{l}\text { Lattice } \\
\text { parameter }(\mathrm{nm})\end{array}$ & Particle morphology \\
\hline \multicolumn{6}{|c|}{ A. Micron-sized range } \\
\hline $\mathrm{Fe}^{\prime}$ & $0.4-4$ & 3 & bcc & 0.29 & Spherical \\
\hline $\mathrm{Fe}^{2}$ & $1-6$ & 3 & bcc & 0.29 & Spherical \\
\hline $\mathrm{Ni}$ & $0.2-1$ & 0.6 & $\mathrm{fcc}$ & 0.35 & Spherical \\
\hline W & $0.2-3$ & 1 & bcc & 0.32 & Faceted \\
\hline Co & $0.3-2$ & 1 & $\mathrm{fcc}$ & 0.35 & Spherical \\
\hline Element & $\begin{array}{l}\text { Size range } \\
(\mathrm{nm})\end{array}$ & $\begin{array}{l}\text { Average size } \\
(\mathrm{nm})\end{array}$ & $\begin{array}{l}\text { Crystal } \\
\text { structure }\end{array}$ & $\begin{array}{l}\text { Lattice } \\
\text { parameter }(\mathrm{nm})\end{array}$ & Particle morphology \\
\hline \multicolumn{6}{|c|}{ B. Nanosized range } \\
\hline $\mathrm{Fe}$ & $10-2000$ & 30 & bcc & 0.29 & Spherical \\
\hline $\mathrm{Ni}$ & $10-500$ & 27 & $\mathrm{fcc}$ & 0.35 & Spherical \\
\hline W & $6-5000$ & 37 & bcc & 0.32 & Spherical \\
\hline Co & $10-1000$ & 33 & $\mathrm{fcc}$ & 0.35 & Spherical \\
\hline
\end{tabular}

\section{Conclusion}

Ballistic aerosols as well as manufactured micron-sized and nanosized particles representing the ballistic alloy compositions $\mathrm{W}, \mathrm{Fe}, \mathrm{Ni}$, and $\mathrm{Co}$, were characterized and exposed to cytotoxic experiments using a human lung epithelial A549 model cell line. Earlier work by Machado et al has shown that ballistic aerosol collections of aggregated nanoparticles averaging approximately $10 \mathrm{~nm}$ were highly toxic to this cell type in a very short time (48 hours), ie, the cells were killed so rapidly that there was no time to produce any anti-inflammatory markers, eg, interleukins 6 and $8 .^{8}$ These are anti-inflammatory cytokines that stimulate the immune response to trauma that leads to inflammation, including tissue damage. Nanoparticles of, eg, Fe/W, W/Ni and W/Co exhibit noticeable cytotoxicity, but not as significantly as the mixture of ballistic aerosol. Although the commercially manufactured nanosized and micron-sized particles do not contribute significantly to epithelial cell death, there is a measurably greater cytotoxicity with the nanopowder particulates in contrast with the micron-sized particulates, in agreement with other comparative studies. ${ }^{2,3,5}$ The characterization of the ballistic aerosol particles in comparison with the commercial (manufactured) powders shows similar morphologies for both the nanosized and micron-sized using SEM and TEM analyses. Energy-dispersive spectrometry elemental mapping sequences of the collected ballistic aerosols show that the larger (micron-sized) particles are mainly Fe, but reveal mixtures of primarily $\mathrm{W}$ and $\mathrm{Ni}$ comprising the surrounding nanosized aggregated particles. There are limited observations regarding small particles and aerosols, chemistries, size distributions, and cytotoxic responses for these types of alloys and elements. Likewise, studies performed using other particles with a vast compositional range and microstructural characteristics exhibit respiratory inflammatory effects.

Taken together, the results of cytotoxicity assays indicate potential respiratory effects for manufactured elemental (W, Ni, Fe, Co) nanoparticles, especially $\mathrm{W}$ and Fe, while the collected ballistic aerosols, either $\mathrm{W}-\mathrm{Ni}-\mathrm{Co}$ or $\mathrm{W}-\mathrm{Ni}-\mathrm{Fe}$, exhibit extreme cytotoxicity, and potential for serious health effects, especially in the short term. While $\mathrm{W}$ is normally not toxic in bulk or micron-sized form, nanosized $\mathrm{W}$ exhibits measurable cytotoxicity.

\section{Acknowledgments}

This research was supported in part by the US Army Research Laboratory, Aberdeen Proving Ground, MD, and a National Institutes of Health-funded Research Centers in Minority Institutions Grant. A Mr and Mrs MacIntosh Murchison Chair at the University of Texas at El Paso also provided partial support. RMS is supported by a RISE Graduate Student Fellowship grant. The two cores used for the cell analyses were the Cell Culture and High Throughput Screening Core Facility and The Biomolecule Analysis Core Facility.

\section{Disclosure}

The authors report no conflicts of interest in this work.

\section{References}

1. Donaldson K, Stone V, Clouter A, et al. Ultrafine particles. Occup Environ Med. 2001;58(3):211-215.

2. Murr LE, Soto KF, Garza KM. Health hazards of manufactured, natural environmental and anthropogenic atmospheric nanoparticulate materials: Past, present and future. In: Ali N, Ahmed W, Oechsner A, editors. Biomaterial and Biomedical Engineering. Zurich, Switzerland: Trans Tech Publishers; 2008.

3. Pope CA IIIrd, Dockery DW. Health effects of fine particulate pollution: Lines that connect. J Air Waste Manag Assoc. 2006;56(10):709-742. 
4. Soto KF, Garza KM, Shi Y, Murr LE. Direct contact cytotoxicity assays for filter-collected, carbonaceous (dust) nanoparticulate. Material and observations of lung cell response. Atmos Environ. 2008;42: 1970-1982.

5. Oberdörster G. Pulmonary effects of inhaled ultrafine particles. Int Arch Occupat Environ Health. 2001;74(1):1-8.

6. Machado BI, Murr LE, Suro RM. Characterization and cytotoxic assessment of ballistic aerosol particulates for tungsten alloy penetrators into steel target plates. Int J Environ Res Public Health. 2010;7(9): 3313-3331.

7. Guilmette RA, Parkhurst MA, Miller G, et al. Human Health Risk Assessment of Capstone Depleted Uranium Aerosols. Attachment 3 of Depleted Uranium Aerosol Doses and Risk: Summary of US Assessments. Columbus, OH: Battelle Press; 2006.

8. Gold K, Cheng TD, Holmes A. A quantitative analysis of aerosols inside an armored vehicle perforated by a kinetic energy penetrator containing tungsten, nickel and cobalt. Mil Med. 2007;172(4):393-398.

9. Pizaña C, et al. Solid-state flow, mechanical alloying, and melt-related phenomena for [001] single-crystal W ballistic rod penetrators interacting with steel targets. Mater Sci Eng A. 2006;428:301-313.
10. Murr LE, Pizaña C. Dynamic Recrystallization: The dynamic deformation regime. Metallurgical and Materials Transactions A. 2008; 38(11):2611-2628

11. Garza KM, Soto KF, Murr LE. Cytotoxicity and reactive oxygen species generation from aggregated carbon and carbonaceous nanoparticulate materials. Int J Nanomed. 2008;3(1):83-94.

12. Oberdörster G, Ferin J, Lehnert BE. Correlation between particle size, in vivo particle persistence, and lung injury. Environ Health Perspect. 1994;102(Suppl 5):173-179.

13. Buzea C, Pacheco J, Robbie K. Nanomaterials and nanoparticles: Sources and toxicity. Biointerphases. 2007;2(4):17-71.

14. Dobravolvkala MA, McNeil SE. Immunological properties of engineered nanomaterials. Nat Nanotechnol. 2007;2(8):469-478.

15. Kennedy C, Murr L.E. Comparison of tungsten heavy-alloy rod penetration into ductile and hard metal targets: Microstructural analysis and computer simulations. Mater. Sci. Eng. 2002; 325:131-143.
International Journal of Nanomedicine

\section{Publish your work in this journal}

The International Journal of Nanomedicine is an international, peerreviewed journal focusing on the application of nanotechnology in diagnostics, therapeutics, and drug delivery systems throughout the biomedical field. This journal is indexed on PubMed Central, MedLine, CAS, SciSearch $\AA$, Current Contents ${ }^{\circledR} /$ Clinical Medicine,

\section{Dovepress}

Journal Citation Reports/Science Edition, EMBase, Scopus and the Elsevier Bibliographic databases. The manuscript management system is completely online and includes a very quick and fair peer-review system, which is all easy to use. Visit http://www.dovepress.com/ testimonials.php to read real quotes from published authors. 